\title{
A Produção de Conhecimentos na Interface entre as Ciências Sociais e Humanas e a Saúde Coletiva'
}

\section{The Intersection of Knowledge between Social and Human Sciences and Public Health}

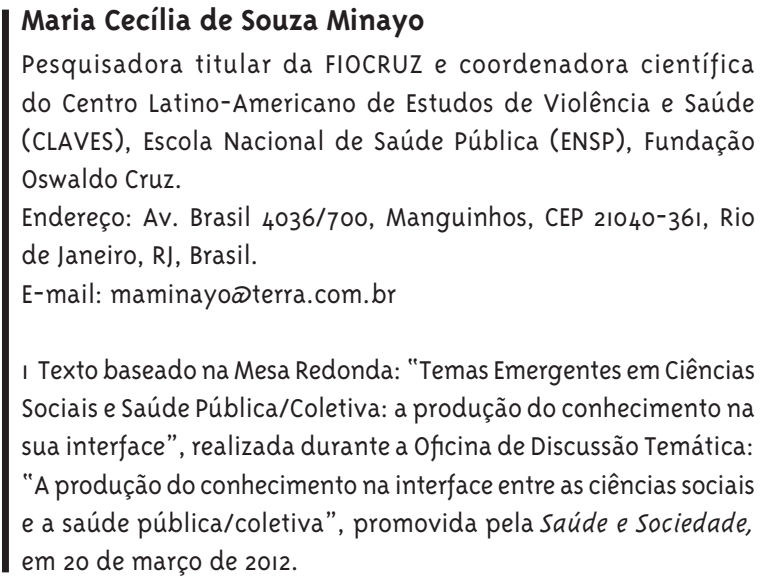

\section{Resumo}

Este artigo trata da intercessão, no âmbito do conhecimento, entre as ciências sociais e humanas e a saúde coletiva. Parte-se do legado das ciências sociais clássicas, discute-se esse aporte, debate-se como e em que medida as ciências sociais e humanas em saúde constituem um subcampo que, por sua vez, articula diversas racionalidades. 0 texto se baseia numa pesquisa sobre a produção científica das sete principais revistas da área: Revista de Saúde Pública; Cadernos de Saúde Pública; Ciência \& Saúde Coletiva; Saúde e Sociedade, Physis, Interface e História, Ciência e Saúde no período de janeiro de 2011 a agosto de 2012 (20 meses). Foram ao todo 1757 artigos publicados nessas revistas, sendo 545 (31,0\%) sobre ciências sociais e saúde ou fazendo interface desse campo com a saúde coletiva. 0 artigo se debruça na análise dessa produção e conclui: que é pujante a participação das ciências sociais e humanas no campo da saúde; que existe um polo irradiador de conhecimentos que parte de autores seminais, mas já conta com a contribuição de estudiosos importantes de segunda e terceira geração; e que os problemas referidos pelos cientistas sociais e de humanidades da área de saúde são os mesmos que hoje ocupam os teóricos sociais, filósofos e historiadores do mundo inteiro.

Palavras-chave: Ciências Sociais e Saúde; Ciências Humanas e Saúde; Saúde Coletiva; Teoria Social. 


\section{Abstract}

This paper discusses the intersection of knowledge between the social sciences and public health. The author begins discussing the legacy of classic social science and debates how and to what extent the social and human sciences constitute a subfield which, in turn, articulates different rationalities. The text is based on a survey about the scientific production of seven important Brazilian journals in the field: Journal of Public Health, Reports in Public Health, Science \& Public Health, Health and Society, Physis, Interface and History, Science and Health in the period of January 2011 to August 2012 (20 months). There were a total of 1757 articles published in these journals, of which 545 (31.0\%) on social sciences and health or interfacing with the field of public health. The article focuses on the analysis of this literature and concludes that: participation of social sciences and humanities in health is thriving; seminal authors constitute an irradiator polo of knowledge, but the contribution of scholars from second or third generation is already seen. It is also true that the problems referred to by social and human scientists are the same that occupy today social theorists, philosophers and historians worldwide.

Keywords: Social and Health Sciences; Human Sciences and Public Health; Public Health; Social Theory.

\section{Introdução}

Este artigo trata da intercessão, no âmbito do conhecimento, entre as ciências sociais e humanas e a saúde coletiva. Parto do legado das ciências sociais clássicas, discuto esse aporte e faço um debate com dados da produção nacional e com a visão internacional do campo, levando em conta o que aqui considero o subcampo das ciências sociais e humanas em saúde.

Em editorial para os Cadernos de Saúde Pública (2010), o coordenador científico do SciELO, professor Rogério Meneghini, escreveu textualmente: “as ciências da saúde representam atualmente uma área científica de ponta no mundo, devido à sua crescente presença em distintos campos de conhecimento, desde as chamadas ciências duras até a medicina, epidemiologia, sociologia e ciências políticas. Não surpreendentemente, as bases de dados científicos enfrentam dificuldades em classificar as ciências da saúde em categorias de conhecimento mais amplas, como ciência ou sociologia" (Meneghini, 2010, p. 1058-1059). Continuando sua reflexão, esse autor ressalta que embora o Brasil tenha ocupado apenas o $13^{\circ}$ lugar na produção científica global em 2008, segundo a Web of Science, a produção das ciências da saúde chegou ao $3^{\circ}$ lugar mundial e a da saúde coletiva, especificamente, ao $4^{\mathrm{o}}$ lugar, segundo estatísticas do SciELO.

Com certeza, sob qualquer aspecto que observemos, a colaboração das ciências sociais e humanas em intercessão com a saúde coletiva também ocupa um espaço importante na produção científica nacional e internacional. É exatamente essa contribuição difícil de ser classificada, segundo palavras de Meneghini, que buscarei analisar neste trabalho.

Primeiramente é necessário definir o que denomino "ciências sociais e humanas", para o que seguirei os estatutos clássicos (Wallerstein, 1999), uma vez que a produção dessas áreas no campo da saúde não pode prescindir de uma incursão por seus fundamentos epistemológicos. Não é fácil essa definição e me valho da que oferecem Giddens e Turner (1999) que em lugar de formalizarem o conceito falam do que se realiza ao interior dessas ciências: discussão sobre seu próprio status frente às ciências naturais; natureza das leis e generalizações 
que podem ser observadas e estabelecidas; relações sociais e relações de poder; caráter, forma e história da evolução e das transformações das instituições; e significados, representações e interpretações da ação humana. As ciências sociais e humanas se apresentam com grande diversidade de correntes teóricas, estruturas corporativas e comunidade de estudiosos (Alexander, 1999).

Geralmente, como em qualquer área, a construção do conhecimento em ciências sociais e humanas configura disciplinas que se constituem com teorias, métodos e fronteiras próprias. Portanto, a organização disciplinar define o que se pensa, como se pensa, o que se produz, o que se ensina e o que não é de sua competência. Podemos dizer que o tronco-mãe das ciências sociais é a sociologia (Parsons, 1949), disciplina cuja invenção remonta ao final do século XIX, quando também se dá a origem de todas as outras que são catalogadas hoje no campo das ciências sociais - como é o caso da história, da economia, da ciência política e da antropologia. Juntando-se a esse conjunto os estudos filosóficos, de subjetividade na psicologia social, de historiografia, de história oral, de ética e bioética, temos o que denominamos ciências sociais e humanas. É preciso ficar claro que falamos aqui da constituição da ciência moderna tal qual a conhecemos hoje, pois se formos ao passado, a fonte originária de todos os campos que dizem respeito à ação e à significação humanas, na verdade, remonta aos gregos.

No entanto, para Wallerstein (1999), as mudanças no cenário mundial, ocorridas depois da Segunda Guerra Mundial, derrubaram a lógica da segmentação, diluindo fronteiras e tornando impossível defender as divisões disciplinares que hoje desenham o campo das questões sócio-históricas culturais e intersubjetivas. A evocação dessa visão aberta vem sendo seguida por muitos autores, entre eles Giddens e Turner (1999), segundo os quais tais mudanças se acentuaram depois de 1989, ano-marco relevante pelo peso histórico e simbólico da queda do muro de Berlim. Assim, entendo com esses autores que os parâmetros teóricos, espaciais, filosóficos e metodológicos das Ciências Sociais e Humanas nascidas na Europa ao final do século XIX se tornaram insuficientes por vários motivos: pela hegemonia econômica, política, cultural e científica dos Esta- dos Unidos; pelo ressurgimento político do mundo oriental; pela cada vez maior internacionalização e globalização da economia; pelo afrouxamento das fronteiras entre Estado, Sociedade Civil e Mercado e pela crise do petróleo que propiciou a expansão do movimento ambientalista em todo o mundo. Também é importante assinalar o movimento cultural global, mormente ocidental, que expandiu os direitos das mulheres e o conceito de gênero, a ideia da especificidade dos direitos dentro do ciclo de vida, a valorização dos grupos étnicos e de segmentos sociais específicos como os homossexuais e os portadores de deficiência, entre outros importantes acontecimentos históricos que nunca terminamos de vivenciar.

A informação mais relevante sobre o movimento das transformações que diluíram as fronteiras disciplinares é que a maioria deles ocorreu por causa de inovações científicas e tecnológicas adotadas na produção de bens e serviços, que trazem soluções importantes frente aos problemas da humanidade mas também retornam como grandes desafios e novos problemas para seus campos específicos e para a sociedade (Unesco, 2010). É o caso do acelerado desenvolvimento da microeletrônica, das áreas de informação e comunicação e da biologia. A interação entre o conhecimento gerado e os artefatos construídos é um capítulo fundamental nas profundas transformações contemporâneas. Por exemplo, a globalização da economia, da cultura e das comunicações veio colocar novas questões para as ciências sociais e humanas, criadas dentro da lógica do Estado Nação e da sociedade industrial.

No entanto, as denominações disciplinares continuam a existir, institucionalizadas como formas de poder (Bourdieu, 1984; 1996) nas organizações corporativas, nos departamentos, nos programas de ensino, nos Congressos Científicos, nos periódicos e nas classificações bibliográficas, dentre outros dispositivos. E quanto ao subcampo das ciências sociais e humanas em interação com a saúde coletiva, tanto vamos encontrar a dificuldade de delinear fronteiras como produções que podem ser encaixadas, por sua especificidade, na categorização disciplinar.

Tendo em vista os pressupostos anteriores, este artigo foi construído a partir das seguintes premissas: (1) o fato das ciências sociais e humanas em 
saúde não constituírem um campo de conhecimento autônomo e, sim, um subcampo dessas áreas; (2) a constatação, amparada em vários teóricos, de que as divisões disciplinares que separavam essas áreas no interior do setor saúde estão cada vez mais se diluindo; e (3) a visão também compartilhada, de que os fundamentos das ciências sociais e humanas constituem artefatos heurísticos que permitem encontrar a inteligibilidade do universo das construções humanas, das quais a saúde é um símbolo fundamental, como já asseverava Lévy-Strauss, em 1950, na introdução à obra de Marcel Mauss a respeito de estudos que abrangeram e compararam sistemas de crenças sobre cura de diferentes tribos das ilhas do Pacífico:

"O esforço irrealizável, a dor intolerável, o prazer e o aborrecimento ocorrem por meio das particularidades individuais, mas, sobretudo, por meio de critérios sancionados pela aprovação ou desaprovação coletiva [...] Em face das concepções racistas que querem ver no homem o produto de seu corpo, ao contrário, é o homem, sempre e em toda parte, que faz de seu corpo um produto de suas técnicas e de suas representações” (p. XIII-XIV).

Ou o sobejamente conhecido pensamento de Boltanski:

"Os determinismos sociais não informam jamais o corpo de maneira imediata”, por meio de uma ação que se exerceria diretamente sobre a ordem biológica sem a mediação do cultural que os retraduz e os transforma em regras, em obrigações, em proibições, em repulsas ou desejos, em gostos e aversões" (1979, p. 119).

\section{Caminhos do Pensamento}

Para elaboração deste texto parti da leitura crítica de alguns autores internacionais e referenciais para as Ciências Sociais e Humanas e de autores nacionais que pesquisam e estudam as Ciências Sociais e Humanas na área da Saúde. Trabalhei com um levantamento e revisão preliminar sobre a produção científica contemporânea na área, tomando como base todos os artigos sobre saúde coletiva publicados nos últimos 20 meses (de janeiro de 2011 a agosto de 2012), nas sete revistas mais citadas: Revista de
Saúde Pública, Cadernos de Saúde Pública, Ciência \& Saúde Coletiva, Physis, Interface, e História, Ciência e Saúde e Saúde e Sociedade. Do total de 1757 encontrei 545 (33,0\% do total) textos que são de ciências sociais e humanas stricto sensu ou de saúde coletiva que utilizam o referencial teórico ou metodológico dessas áreas. Li os títulos, resumos, palavras-chave e a metodologia de cada um dos selecionados, a partir da sua versão completa na base de dados SciELO (www.scielo.org), na qual todos esses periódicos estão incluídos.

As categorias observadas foram: ciências sociais e humanas em saúde; ciências sociais e saúde; ciências sociais em saúde; ciências sociais e saúde pública/saúde coletiva; ciências sociais nas escolas médicas; antropologia médica e da saúde; sociologia médica e de saúde; história da saúde e de doenças específicas; etnografia e trajetórias de doenças e de instituições de saúde; análises de políticas de saúde; economia da saúde; e abordagem qualitativa (hermenêutica, fenomenológica, etnográfica, histórica) para avaliar concepções de doenças, serviços de saúde, políticas de saúde, instituições de saúde; história de doenças, instituições e biografias; abordagens que articularam estudos antropológicos, sociológicos ou de saúde mental com epidemiologia ou clínica.

Levei em conta, sobretudo, o escopo deste artigo que é observar a intercessão das ciências sociais com a saúde coletiva. Deu muito trabalho esse labor artesanal, mas ele me trouxe recompensas que poderiam ser ainda maiores, não fosse a escassez de tempo que tive para refletir sobre o material e redigir o artigo. Devo mencionar que não tive condições de me aprofundar na análise da qualidade teóricometodológica do material. Essa é uma limitação que lastimo, uma vez que uma reflexão minuciosa exigiria muito mais investimento. Portanto, considero que várias questões permanecerão aqui no plano das hipóteses e merecerão aprofundamento.

\section{Resultados}

A busca ativa de artigos que fazem intercessão entre saúde coletiva e ciências sociais nas referidas revistas apontou a existência de 545 num total de 1757 textos dos mais diferentes campos e temas re- 
cobertos pela saúde coletiva nos 20 meses, ou seja, entre janeiro de 2011 e agosto de 2012 (tabela 1). Esse total corresponde a $31 \%$ dos artigos publicados nos citados periódicos, nesse intervalo de tempo. Sobre o conjunto dos dados é importante tecer algumas considerações.

\section{Tabela I - Número e proporção (\%) de artigos que fazem interface entre Ciências Sociais e Humanas e Saúde Coletiva (janeiro de 20II a agosto de 2012)}

\begin{tabular}{lccc} 
Nome da Revista & Total de artigos & Total SC/C. Sociais e Humanas & $\%$ \\
Ciência E Saúde Coletiva & 633 & 201 & $33,4 \%$ \\
Cad. Saúde Púbica & 404 & 41 & $14,3 \%$ \\
Rev. Saúde Pública & 229 & 16 & $7,0 \%$ \\
Saúde e Sociedade & 149 & 89 & $59,7 \%$ \\
Physis & 117 & 64 & $54,7 \%$ \\
Interface & 125 & 78 & $62,4 \%$ \\
Historia, Ciência, Saúde & 100 & 56 & $56,0 \%$ \\
\hline Total & 1757 & 545 & $31,0 \%$ \\
\hline
\end{tabular}

O primeiro ponto a ser observado é que as duas revistas Qualis A e com maior índice de impacto em nossa área são as que menos divulgam estudos em que entram especificamente as ciências sociais e humanas, embora o façam: em 20 meses, Cadernos de Saúde Pública publicou 41 artigos (14,3\%); e Revista de Saúde Pública, 16 (7\%). Talvez por apresentarem em maiores proporções estudos da área de epidemiologia, a mais consolidada e corporativamente organizada dentre as que conformam o campo da saúde coletiva, elas sinalizem as dificuldades que as Ciências Sociais e Humanas ainda têm para ter sua contribuição e lógica aceitas no nicho mais valorizado.

Em números absolutos (221 artigos), a Revista Ciência \& Saúde Coletiva é a que mais publicou, no período, artigos que fazem intercessão entre Saúde Pública e Ciências Sociais e Humanas. No entanto, por ser um periódico que divulga textos de todos os campos de conhecimento que fazem interface com a área, percentualmente, ela está colocada no $3^{\circ}$ lugar $(33,4 \%)$.

Todas as demais revistas publicaram mais de 50\% dos seus artigos em Ciências Sociais e Humanas, cabendo destacar, pela ordem, Interface $(62,4)$; Saúde e Sociedade (59,7\%); História, Ciência e Saúde (56,0\%) e Physis (54,7\%).

Assim, em termos gerais, todas as revistas me- lhor classificadas de nossa área estão divulgando, em elevadas proporções, a produção científica das Ciências Sociais e Humanas em intercessão com a Saúde Coletiva. O caso do menor aporte de textos por parte da Revista de Saúde Pública e dos Cadernos de Saúde Pública deve ser analisado como compreensível dentro da lógica biomédica e quantitativista da epidemiologia. Dentre os autores que tratam dessa relação, cito Almeida Filho (200o) que, ao se referir à contribuição da epidemiologia, ora a coloca como instrumento privilegiado para a ação, ora como o próprio campo da saúde pública. Nesse segundo caso, o autor reduz a área a uma visão disciplinar e passa ao largo da análise científica que as Ciências Sociais e Humanas (frequentemente tratadas pela epidemiologia como senso comum) podem aportar para compreensão das questões que afetam a saúde. Também, é claro que, dentro da linguagem acadêmica, é muito mais simples e legitimado o raciocínio epidemiológico que se fundamenta em evidências matemáticas, segue a tradição das ciências da natureza e se ancora na filosofia da consciência, em contraposição ao teor reflexivo dos textos de ciências sociais e humanas que privilegiam a compreensão e a intersubjetividade, dentro da lógica da filosofia da comunicação (Habermas, 1987). O ideal seria que fôssemos capazes de valorização do aporte científico de ambos os campos, triangulando conhecimentos, 
métodos, técnicas e análises, frente a problemas de saúde e do setor, geralmente muito complexos (Minayo e col., 2003).

Tratarei a seguir de categorizar os artigos selecionados, seguindo o pensamento de Giddens e Turner (1999), propondo a seguinte classificação: (1) os que tratam do status das ciências sociais em sua intercessão com a epidemiologia e com a saúde coletiva; (2) os que fazem interpretação das atividades humanas no campo da saúde; (3) os que tratam do caráter, da forma, da evolução histórica e do desempenho das instituições de saúde; (4) os que se referem às relações sociais, de poder e aos profissionais dentro do campo da saúde; (5) os que estudam os sentidos atribuídos pelos atores ao objeto da saúde que são a vida, a qualidade de vida e a morte. E acrescentarei um item relativo a (6) abordagens novas que trazem para o campo demandas importantes da pauta dos direitos em saúde, como questões de gênero, de cidadania por grupos etários e por etnia.

Buscarei, a partir dessa classificação, desvendar um pouco melhor o conteúdo dos artigos, embora não tenha me proposto a quantificar tais contribuições.

(1) Sobre o status das ciências sociais e humanas em saúde: revisões sobre o campo, compreendendo textos de antropologia, sociologia, história, saúde mental; artigos sobre teorias históricas e análise dos fatos, das políticas, da sociedade civil, do trabalho, do controle social, dos movimentos sociais e das teorias de redes aplicadas ao sistema de saúde.

(2) Sobre instituições, com aplicação de vários aportes teóricos: análises econômicas, sociológicas, antropológicas e de ciências políticas a respeito do SUS como sistema; sua territorialização, regulação, relação e tensão com a lógica privada da atenção à saúde e por comparação com sistemas de outros países; estudos compreensivos e avaliativos sobre a organização da atenção primária, estratégia saúde da família, centros de saúde, serviços especializados como os CAPS, unidades de emergência e urgência, hospitais gerais e hospitais especializados, modelos institucionais alternativos de tratamento e sobre a influência da cultura brasileira nas instituições de saúde.
(3) Sobre interpretação das ações e fenômenos humanos e sociais que afetam a saúde: estudos sobre morte; aborto, terapias específicas sob a ótica dos usuários dos serviços de saúde mental, saúde bucal, deficiência física e mental, nutrição; análises históricas e antropológicas das doenças e do seu enfrentamento por pacientes e por profissionais de saúde. (4) Relações de poder e profissionais: gestão dos serviços; relações interprofissionais nas diversas áreas que se articulam no SUS como medicina, enfermagem, psicologia, fisioterapia, educação física, nutrição; cuidadores formais e informais; análise e avaliação de serviços e de intervenções; análises de controle social; desigualdades no acesso à saúde; estigmas e preconceitos.

(5) Sentidos atribuídos pelos atores à saúde, doença e ao sistema: este é o item que contém maior número de artigos, utilizando, geralmente, abordagem etnográfica, interacionista, fenomenológica ou hermenêutica sobre os mais diferentes temas: doenças crônicas como as cardiovasculares, hipertensão, diabetes, obesidade, osteomusculares e desnutrição; doenças infecciosas como AIDS, as sexualmente transmissíveis, dengue, malária, varíola, poliomielite; sobre doenças mentais sob suas diversas manifestações; agravos por causas externas, álcool e drogas como homicídios, suicídios e acidentes; deficiências físicas e mentais; qualidade de vida; conhecimento popular; religião e saúde; corpo, beleza e saúde; cuidados; humanização; finalmente, sobre o sentido das inovações em tratamentos, sobretudo os relacionados à aplicação de biotecnologia.

(6) Saúde de grupos específicos: por gênero (homens, mulheres, homoafetivos); por faixas etárias (recémnascidos, crianças, adolescentes, homens, adultos e idosos e por integração intergeracional); por inserção social: prisioneiros, trabalhadores dos mais diferentes setores e populações indígenas.

Alguns temas tornaram-se recorrentes nas ciências sociais e humanas a partir da segunda metade do século XX exatamente porque tomaram a agenda pública mundial e provocaram grandes transformações culturais, como a clivagem de gênero; as questões da cidadania e dos direitos em saúde por faixas etárias; saúde e trabalho; ética e bioética; riscos biológicos provenientes de da biotecnologia, 
dos experimentos e dos medicamentos; o lugar privilegiado da comunicação e da informação que, no dizer de Hobsbawm (1998), constituem a estrada por onde passa a sociedade contemporânea e também, de importância fundamental, a questão ambiental. Pois bem, todos esses assuntos são tratados por autores que escreveram, no intervalo de tempo citado, na área da saúde sob a ótica das ciências sociais e humanas. Alguns temas, ainda que presentes, são pouco estudados, como a economia da saúde, a relação entre o social e o ambiental, a influência dos avanços da biologia na saúde coletiva e os estudos dentro da perspectiva interdisciplinar.

As abordagens conceituais e metodológicas são as mais diversas, passando por teorias sociais que privilegiam o papel do ator, os estudos institucionalistas, a historiografia e a história oral, as abordagens econômicas, a fenomenologia, o compreensivismo, a hermenêutica, o referencial marxista, as teorias empiristas, a etnografia, a etnometodologia e, embora em resquício, algumas abordagens funcionalistas.

\section{Discussão}

Buscarei dialogar os achados deste artigo com questões levantadas por cientistas sociais brasileiros sobre o campo e a produção científica e a literatura internacional, chamando atenção para alguns pontos. De início quero ressaltar uma frase de Barros e Spadacio com a qual muito me identifiquei: "existe uma terceira geração de cientistas sociais no campo da saúde brasileira; as Ciências Sociais e Humanas em Saúde são uma aplicação em um campo que 'consome' ciências para gerir o Sistema Único de Saúde; os nossos esforços e posicionamentos no presente, ainda que dirigidos pelo fato de não conhecermos o desfecho, permitem-nos potencializar a natureza e o espírito humanos para uma vida melhor. Assim, compreendemos, conclusivamente, que é fundamental produzir [...] informações, sentimentos, processos, ações e significados, que explicitem narrativas fluidas, flexíveis e reflexíveis sobre como as pessoas interpretam seus mundos sociais" (Barros e Spadacio, 2011, p. 50-56).

Continuando na direção que assinalam os citados autores, chamou-me atenção o fato de que quase to- dos os autores considerados referenciais e históricos de nossa área estão presentes com artigos e posições na literatura aqui consultada, evidenciando que continuam ativos e atualizados em suas reflexões e contribuições. Citarei, como exemplo, apenas uma referência de cada um deles - embora alguns tenham vários artigos dentro do período estudado: Nunes (2012); Canesqui (2011); Luz e Sabino (2011), Loyola (2012); Minayo (2012); Gomes e colaboradores (2011); Combinato e Queiroz (2011); Minayo-Gomez e colaboradores (2011); Iriart e Carrara (2012); Deslandes e colaboradores (2011); Camargo Júnior (2011); Alvarenga e colaboradores (2011); Ianni (2011). Alguns desses autores pertencem à segunda geração formadora de novos pesquisadores, gestores e estudiosos.

o que considero mais notável, porém, é que a maioria absoluta da produção da qual falo aqui, provenha de autores novos. Ou seja, não são autores reconhecidos pelo lugar privilegiado que ocupam na área, são discípulos: alunos, ex-alunos, orientandos e ex-orientandos, estudantes, pesquisadores, professores e profissionais que atuam nos serviços e na gestão. São pessoas que beberam na literatura que lhes foi oferecida pelos seus mestres o sorvo da contribuição das ciências sociais e humanas e passaram a aplicá-lo em suas análises sobre os problemas de saúde.

O segundo ponto que gostaria de ressaltar a partir do rico acervo analisado é que os conhecimentos gerados e as questões levantadas pelos autores referenciais brasileiros do campo das ciências sociais e humanas continuam válidos e presentes nas indagações dos pesquisadores do mundo inteiro. Por exemplo, continuam a nos desafiar hoje, como ontem, os temas da relação entre estrutura e sujeito (Bourdieu, 1984; Giddens, 1999; Minayo, 2001); o papel do sujeito na história (Giddens, 1995; Hans, 1999; Heritage, 1999; Touraine, 1984; Bourdieu, 1996; Minayo, 2001) como se dá a institucionalização das estruturas (Bourdieu, 1984; Giddens, 1995); o papel da cultura e das representações (Hans, 1999; Schutz, 1987); Heritage, 1999; Minayo, 2010); o papel das interações simbólicas (Joas, 1999) como as mudanças sociais ocorrem e que mudanças no campo social e de outras áreas científicas exigem novas abordagens das ciências sociais e saúde (Miliband, 1999; Luhmann, 2006). Esse conjunto de questões a que os 
clássicos se dedicaram, criando teorias, conceitos e métodos para abordá-los, estão também no campo da saúde e na maioria dos textos lidos por mim.

Um terceiro ponto a considerar trata de uma queixa frequente dos cientistas sociais de formação que atuam na área de saúde. Vários deles sempre se lastimam que os profissionais da área absorvem superficialmente as teorias e, frequentemente, tomam o social apenas como campo de abordagem, sem debater teoricamente os dados empíricos. Nesse sentido, se destacam as críticas de Canesqui (2011) e, recentemente, Gomes e Silveira (2012), dentre outros. Ainda que a observação e o argumento sejam verdadeiros - e não podemos esperar que todos os profissionais de saúde se transformem em cientistas sociais - também aqui precisamos ampliar mais nossa reflexão. Giddens e Turner (1999), no livro Teoria Social, discutem à exaustão o atual e sempre permanente debate sobre o caráter analítico e teórico das ciências sociais versus sua vocação empírica.

Esses autores mostram que sobre essa dualidade, os principais autores - inclusive eles próprios que assinam a introdução à obra - nunca se puseram de acordo. Por exemplo, enquanto Giddens (1999) ressalta que o foco no uso metodológico da linguagem pode mostrar-se relevante para a teoria social, Turner (1999) defende o caráter teórico e analítico dessas ciências. Na verdade, para os que fazem trabalho de campo, os debates teóricos costumam ser de escasso interesse ou relevância. E na obra já citada há autores que professam o empirismo filosófico, segundo o qual o significado das teorias e dos conceitos está presumivelmente ligado a observações diretas, dentro da linha do positivismo que continua vivo e atravessando as ciências naturais e as ciências sociais e humanas.

Há também os que defendem a empiria a partir das tradições compreensivistas das comunicações e da observação dos contextos e do mundo da vida, como é o caso da fenomenologia sociológica associada aos estudos de Schutz (1987), a hermenêutica desenvolvida por Gadamer (1999) ou Paul Ricoeur (1978), a teoria crítica apresentada por Habermas (1987) ou a teoria da prática originada em Bourdieu (1996). Muitos autores professam uma releitura do marxismo (Miliband, 1999) ou das teorias sistêmicas a partir do pensamento complexo, desenvolvido ini- cialmente pelas ciências naturais (Luhmann, 2006). Desta forma, a apropriação das ciências sociais e humanas pelos profissionais e pesquisadores da área de saúde em geral vivencia as mesmas dificuldades que o campo das teorias sociais e filosóficas stricto sensu apresentam.

Merece também ser debatida a ideia defendida quase como um mantra por alguns autores de que as ciências sociais e humanas têm pouco espaço de publicação nos veículos da área de saúde (Leal e Camargo Junior, 2012; Luz e Sabino, 2011; Loyola, 2012). Creio que essa afirmativa precisa ser revista a partir dos dados constantes na tabela l, uma vez que os números apontados por todas as revistas de maior circulação da área revelam o contrário. Diferente é falar sobre o peso internacional de nossas publicações, o que, na verdade merece uma reflexão-ação específica. Creio que, na medida em que determinados temas que tratamos são universais, precisamos de mais esforço para dialogar com pesquisadores de outros países.

Gostaria de mencionar também, embora não tenha sido objeto de minha análise, a grande quantidade de livros de ciências sociais e humanas em saúde, obras de autores referenciais e novos, na pauta das editoras científicas. Assinalo apenas como exemplo a coleção de Antropologia da Editora Fiocruz que tem 33 livros, muitos já em várias edições, e a de Ciências Sociais e Saúde, que soma 44. Igualmente, a Editora HUCITEC é uma das líderes em publicar estudos de Ciências Sociais e Humanas, e apresenta cerca de 30 títulos em seu catálogo que podem ser considerados como fazendo a intercessão entre saúde coletiva e ciências sociais. Hoje conseguimos uma valorização dos livros tanto abrindo uma base de dados no sistema SciELO (www.scielo.org.br) como um campo específico de avaliação da Coordenação do Aperfeiçamento do Pessoal de Nível Superior do Ministério da Educação (CAPES).

Por fim, faço uma observação sobre a qualidade do material publicado que serviu de base para minhas reflexões. Como avisei na metodologia de elaboração deste texto, não tive condições de fazer uma análise dos conteúdos e nem da coerência entre proposta, objetivos, teoria e métodos. Mas tenho sim, uma hipótese: ao ter analisado textos publicados nas revistas de maior circulação e credibilidade em saúde coletiva, presumo que exista um rigor 
científico no corpo de pareceristas e por parte dos editores. Portanto, suponho também que, na medida do possível, exista qualidade no material publicado. É claro que essa hipótese precisaria ser provada ou refutada, mas lembro aqui a constatação epistemológica de Popper, segundo a qual o critério de validade científica mais importante ainda é a avaliação por pares (Popper, 1949).

\section{Conclusões}

A análise que faço neste texto, creio, pode nos deixar bastante otimistas sobre o trabalho seminal que professores e pesquisadores da área de ciências sociais e humanas vêm fazendo nos cursos de graduação e pós-graduação strictu e latu sensu do setor saúde e que se reflete em publicações científicas. Gostaria de ressaltar que nossos autores seminais que fizeram ou fazem ciências sociais e humanas em saúde constituem-se ainda como verdadeiros polos irradiadores do conhecimento e estão presentes nos artigos aqui levantados. Em razão disso, constatamos uma intercessão cada vez maior e mais profícua da área com a saúde coletiva/pública, enredando novos pesquisadores de segunda e terceira geração que pouco a pouco vão se tornando relevantes para ambos os campos.

A constatação acima não significa um ato de triunfalismo. É fundamental, claro, que a área de saúde coletiva tenha sempre cientistas de formação das áreas sociais e humanas, pois de certa forma eles devem cumprir o papel insubstituível de enfrentar os paradoxos e as contradições de certos temas desafiantes; de desnaturalizar e de problematizar questões que o setor abraça de forma acrítica; e de investir na capilarização da reflexão social e humana dos objetos de saúde, em diferentes níveis e em diferentes aspectos, sem purismo, mas com método e contextualização. Do ponto de vista do método, vale ressaltar que ainda há importantes desafios epistemológicos e práticos a serem enfrentados, como é o caso das abordagens interdisciplinares, ainda tão pouco utilizadas e aprofundadas num campo que reúne várias racionalidades.

Do ponto de vista dos conteúdos, é possível dizer que qualquer tema de saúde é também assunto das ciências sociais e humanas, uma vez que todos dizem respeito à vida, ao adoecimento, à morte, a como as pessoas os pensam e os enfrentam e ao que a sociedade e o setor fazem para gerenciá-los. Por isso, é preciso problematizar o extraordinário avanço científico contemporâneo, sobretudo o das áreas da biologia e da genética, que passaram a modificar uma série de certezas anteriores. As práticas biotecnológicas, especialmente as de reprodução assistida, dos transplantes e implantes de órgãos, tecidos e fluidos, da produção de medicamentos, passaram a romper, inclusive, os contornos do paradoxo entre natureza e cultura. Mas persistem problemas mais comuns da área que exigem investimento, como é o caso das doenças endêmicas e infecciosas, o aumento de doenças e agravos marcados pelo estilo de vida (cardiovasculares, neoplasias, diabetes, violências, obesidade, abuso de drogas), a medicina midiática e as questões ambientais que afetam a sociedade.

Que olhemos para dentro da área com visão crítica mas otimista: é preciso desnaturalizar, entre nós mesmos, os mitos de que publicamos pouco, de que não há onde publicar, de que o status das Ciências Sociais e Humanas merece privilégios nas pautas das revistas, de que é impossível conversar com os epidemiologistas e outros. Ao invés disso, precisamos reafirmar a força de nossa contribuição e reconhecer os novos atores e autores que estão entrando com força e sem pedir licença.

\section{Referências}

ALEXANDER, J. C. A importância dos clássicos. In: GIDDENS, A; TURNER, J. H. (Org.). Teoria social hoje. São Paulo: Editora Unesp, 1999. p. 23-90.

ALMEIDA FILHO, N. A ciência da saúde. Editora Hucitec: São Paulo, 2000.

ALVARENGA, A. T.; VASCONCELLOS, M. P; ADORNO, R. C. F. A contribuição das ciências sociais e humanas na pesquisa, no ensino e na formação em saúde. Saúde e Sociedade, São Paulo, v. 20, n. 1, p.9-11, jan./mar. 2011.

BARROS, N. F.; SPADACIO, C. A formação do pósgraduando no mundo contemporâneo no cotidiano da pesquisa. Saúde e Sociedade, São Paulo, v. 1, n. 20, p. 50-56, 2011.

BOLTANSKI, L. As classes sociais e o corpo. Rio de Janeiro: Graal, 1979. 
BOURDIEU, P. Homo academicus. Paris: Ed. de Minuit, 1984.

BOURDIEU, P. Razões práticas: sobre a teoria da ação. Campinas: Papirus Editora, 1996.

CAMARGO JÚNIOR, K. R. Closing the gap in a generation: Health equity through action on the social determinants of health. Global Public Health, London, , v. 6, p. 102-105, 2011.

CANESQUI, A. M. Sobre a presença das ciências sociais e humanas na saúde pública. Saúde e Sociedade, São Paulo, v. 20, n. 1, p. 16-21, jan. 2011.

COMBINATO, D. S.; QUEIROZ, M. S. A study on death: an analysis based on Vigotski's dialectical method, o9/2011. Ciência \& Saúde Coletiva, Rio de Janeiro, v. 16, n. 9, p. 3893-39oo, fev. 2011.

DESLANDES, S. F. et al. Indicadores das ações municipais para a notificação e o registro de casos de violência intrafamiliar e exploração sexual de crianças e adolescentes. Cadernos de Saúde Pública, Rio de Janeiro, v. 27, n. 8, p. 1633-1645, ago. 2011.

GADAMER, H. G. Verdade e método. Tradução de F. P. Meurer. 3. ed. Petrópolis: Vozes, 1999.

GIDDENS, A. La constitución de la sociedad: bases para la teoría de la estructuracion. Buenos Aires: Ed. Amorrortu, 1995.

GIDDENS, A.; TURNER, J. H. Apresentação. In: . (Org.). Teoria social hoje. São Paulo: Unesp; 1999. p. 8-21.

GOMES, M. H. A.; SILVEIRA, C. Sobre o uso de métodos qualitativos em Saúde Coletiva, ou a falta que faz uma teoria. Revista de Saúde Pública, São Paulo, v. 46, p. 160-165, 2012.

GOMES, R. et al. Os homens não vêm! Ausência e/ ou invisibilidade masculina na atenção primária. Ciência \& Saúde Coletiva, v. 16, p. 983-992, 2011.

HABERMAS, J. Teoría de la acción comunicativa I. Madrid: Taurus, 1987).

HERITAGE, J. C. Etnometodologia. In: GIDDENS, A; TURNER, J. H. (Org.). Teoria social hoje. São Paulo: Editora Unesp, 1999. p. 321-392.

HOBSBAWM, E. Era dos extremos: o breve século XX: 1914-1991. São Paulo: Companhia das Letras, 1998.
IANNI, A. M. Z. Questões contemporâneas sobre natureza e cultura: notas sobre a Saúde Coletiva e a sociologia no Brasil. Saúde e Sociedade, São Paulo, v. 20, n. 1, p. 32-40, 2011.

IRIART, J.A; CAPRARA, A. Novos objetos e novos desafios para a antropologia da saúde na contemporaneidade. Physis: Revista de Saúde Coletiva, Rio de Janeiro, v. 21, n. 4, p. 1253-1268, abr. 2011.

JOAS, H. Interacionismo simbólico. In: GIDDENS, A.; TURNER, J. H. (Org.). Teoria social hoje. São Paulo: Editora Unesp, 1999. p. 127-176.

LEAL, M. B.; CAMARGO JÚNIOR, K. R. Saúde coletiva em debate: reflexões acerca de um campo em construção. Interface - Comunicação, Saúde, Educação, Botucatu, v. 16, p. 53-66, 2012.

LÉVY-STRAUSS, C. Introdution à l'ouevre de Marcel Mauss. In: MAUSS, M. Sociologie et anthropologie. Paris: Presses Universitaire de France, 1950. p. I-XXX.

LOYOLA, M. A. O lugar das ciências sociais na saúde coletiva. Saúde e Sociedade, São Paulo, v. 21, n. 1, p. 9-14, 2012.

LUHMANN, N. System as difference. Organization, Sage publications, New York, v. 13, n. 1, p. 37-57, jan. 2003 .

LUZ, M. T.; SABINO, C. Espelho da alma. Teoria social e subjetivação. Physis: Revista de Saúde Coletiva, Rio de Janeiro, v. 1, p. 237-250, 2011.

MENEGHINI R. Visibilidade internacional da produção brasileira em saúde coletiva. Cadernos de Saúde Pública, Rio de Janeiro, v. 26, n. 6, p. 1058-1059, 2010.

MILIBAND, R. Análise de classe. In: GIDDENS, A; TURNER, J. (Org.). Teoria social hoje. São Paulo: Editora Unesp, 1999. p. 471-502.

MINAYO, M. C. S. Análise qualitativa: teoria, passos e fidedignidade. Ciência \& Saúde Coletiva, Rio de Janeiro, v. 17, n. 3, p. 621-626, mar. 2012.

MINAYO, M. C. S. et al. Possibilidades e dificuldades nas relações entre ciências sociais e epidemiologia. Cadernos de Saúde Pública, Rio de Janeiro, v. 8, n. 1, p. 97-108, jan. 2003. 
MINAYO, M. C. S. O desafio do conhecimento. 12. ed. São Paulo: Editora Hucitec, 2010.

MINAYO, M. C. S. Estrutura e sujeito, determinismo e protagonismo histórico: uma reflexão sobre a práxis da saúde coletiva. Ciência ¿ Saúde Coletiva, Rio de Janeiro, v. 6, n. 1, p. 7-19, jan. 2001.

MINAYO-GOMEZ, C. Produção de conhecimento e intersetorialidade em prol das condições de vida e de saúde dos trabalhadores do setor sucroalcooleiro. Ciência \& Saúde Coletiva, Rio de Janeiro, v. 16, n. 8, p. 3361-3368, ago. 2011.

NUNES, E.D. World Social Science Report: knowledge divides. Ciência \& Saúde Coletiva, Rio de Janeiro, v. 17, n. 7, p. 1925-1932, jul. 2012.

ORGANIZAÇÃO DAS NAÇÕES UNIDAS PARA A CIÊNCIA, EDUCAÇÃO E CULTURA. Relatório de 201o. Divisão de Políticas e Desenvolvimento Sustentável. Paris: Unesco, 2010.
PARSONS, T. The social system. New York: Free Press, 1951.

POPPER, K. The logic of scientific discovery. New York: Basic Books, 1949.

RICOEUR, P. O conflito das interpretações: ensaios de hermenêutica. Tradução de H. Japiassu. Rio de Janeiro: Imago, 1978.

SHULTZ, A. Le chercheur et le quotidien. Paris: Méridiens Klinck-Sieck, 1987.

TOURAINE, A. Le retour de l'acteur. Paris: Fayard, 1984.

TURNER, J. H. Teorização analítica. In: GIDDENS, A; TURNER, J. H. (Org.). Teoria social hoje. São Paulo: Editora Unesp, 1999. p. 229-280.

WALLERSTEIN, I. El legado de la sociología, la promesa de la ciencia social. Caracas: Editorial Nueva Ciudad, 1999. 